\title{
A Lagrangian analysis of the variation in moisture sources related to drier and wetter conditions in regions around the Mediterranean Basin
}

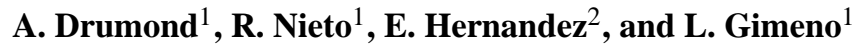 \\ ${ }^{1}$ EPhysLab, Departamento de Física Aplicada, Facultade de Ciencias, Universidade de Vigo, Ourense, Spain \\ ${ }^{2}$ Departamento de Física de la Tierra, Astronomía y Astrofísica II, Universidad Complutense, Madrid, Spain
}

Received: 27 April 2010 - Revised: 7 July 2011 - Accepted: 7 July 2011 - Published: 23 August 2011

\begin{abstract}
Here, we describe our use of the Lagrangian 3-D FLEXPART model to investigate the variation in sources of moisture related to the drier and wetter conditions of the different regions that surround the Mediterranean Basin. We carried out seasonal analyses for the period from March 2000 to February 2005, and identified those years with the highest and lowest rates of precipitation by season, averaged over eight different continental regions. The variation in specific humidity along the 10-day backward trajectories of the particles identified over the target areas was tracked for the selected period, and the characteristics of the moisture sources were then compared between wetter and drier conditions by season. Although they only represented a relatively short period, the results suggest that in most of the years chosen, the moisture sources were more extensive and/or more intense during wetter periods. The contribution of the north Atlantic as a source of moisture is apparent for the Iberian Peninsula, for France and for Central North Africa. Otherwise, the Mediterranean Sea is the predominant source for Eastern North Africa, and for the Italian and Balkan Peninsulas. Local sources provide moisture for the Eastern Mediterranean and Western North Africa.
\end{abstract}

\section{Introduction}

It is now commonly accepted that the precipitation that falls in a given region has one of three origins (Brubaker et al., 1993): (a) moisture already present in the atmosphere, (b) moisture transported into the region from remote sources

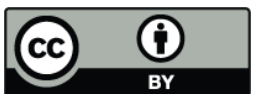

Correspondence to: A. Drumond (anitadru@uvigo.es) by wind (advection), or (c) local evaporation from the earth's surface (recycling). This last term corresponds to the component of the moisture that is recycled. Although its definition varies, recycling is commonly defined to refer to that part of the water that evaporates from a given area and that contributes to the precipitation in that same area (e.g., Eltahir and Bras, 1996). Averaged over long periods, the contribution of source (a) is negligible. Hence, the responsibility for the observed atmospheric moisture in a given region lies with advection and recycling.

Although a number of different approaches can be used to identify geographical sources of moisture, they all suffer from some kind of limitation. Such approaches can be grouped into four categories: (a) studies that calculate recycling ratios (e.g., Eltahir and Bras, 1996; Trenberth, 1999), the main limitation of which is that they cannot determine the specific origin of the nonlocal water; (b) studies that use general circulation models and tracers of water vapour to assess the major sources of evaporation that contribute to precipitation in a different region (e.g., Numaguti, 1999; Bosilovich et al., 2003), in which the source regions must be specified and the results depend on the quality of the modelled data; (c) studies that integrate the atmospheric fluxes of moisture across regional boundaries (e.g., Chen et al., 1994; Liu and Stewart, 2003; Fernandez et al., 2003), which (like type a) also fail to provide information on the geographical sources of the moisture; and (d) studies that quantify the transport using the trajectories of the moisture concerned (e.g., Crimp and Mason, 1999; Knippertz and Martin, 2005). The results of this last type of study can provide full details of the origin of the air mass concerned in three dimensions, but cannot provide any information about the increase and decrease of moisture along the trajectories that could affect the target region.

Published by Copernicus Publications on behalf of the European Geosciences Union. 
In addition to the foregoing types of model, more appropriate and more sophisticated approaches have recently been developed that make use of the full kinematic trajectories calculated from different Lagrangian particle models. The methodology developed by Stohl and James (2004, 2005) determines the net changes in moisture along a large number of back trajectories, which then enables inferences to be made about the sources of moisture in a particular region. In their approach, Sodemann et al. (2008a, b) include the detailed loss of water that occurs through rainfall along the trajectories of the air parcels that subsequently supply the precipitation in the target region.

The Mediterranean region is located at the border between the tropical climate zone and the mid-latitude climate belt, and thereby lies on a considerable environmental meridional gradient (Lionello et al., 2006). The temperate climate of this region is characterised by mild and humid winters and mostly dry summers. The region has a complex morphology, with a high degree of spatial variability in terms of both marine and atmospheric circulation, together with a number of subregional and mesoscale peculiarities.

The Mediterranean hydrological cycle is particularly sensitive to the timing and location of winter storms as they move into the region (Trigo et al., 2002). The influence of the northern Atlantic atmospheric river is felt over an extended area. The pattern of precipitation in the western continental margin is, therefore, determined by the same phenomenon because the coastline is perpendicular to the predominant direction of flow of the atmospheric river (Newell et al., 1992; Zhu and Newell, 1998). In the boreal summer, when the advection of moisture from the Atlantic is weaker and the Hadley cell moves northwards, there is some evidence of a connection with both the Asian and African monsoons ( $\mathrm{Li}-$ onello et al., 2006).

The Mediterranean Sea itself is also an important source of atmospheric moisture and the characteristics of the local water budget influence the amount of moisture that flows into northeast Africa and the Middle East (Peixoto et al., 1982; Ward, 1998). It has been proposed that both past and future global climate changes that affected (or will affect), for example, the characteristics of the storm tracks (Arpe and Roeckner, 1999), together with changes in the conditions of the land surface (Reale and Shukla, 2000), may be linked to significant changes in the hydrological cycle in the Mediterranean region (Bethouk and Gentili, 1999). For this reason, an improved knowledge of the Mediterranean hydrological cycle and of its variability could offer important socioeconomic benefits to these areas.

A number of previous studies identified the geographical sources or sinks of moisture over the Mediterranean Sea using a range of different methodologies (most of them Eulerian in nature) and input data, with results that varied significantly (see the review in Mariotti et al., 2002). For example, Mariotti et al. (2002) carried out a budget analysis to study the contributions to the freshwater flux into the
Mediterranean Sea over the last $50 \mathrm{yr}$, including atmospheric inputs as well as those from river discharges, using recent atmospheric reanalyses and observational datasets. Their analysis showed a flux of moisture from west to east throughout the year, but which had a southward component during the summer, from the eastern Mediterranean into northeast Africa and the Middle East. A contrasting approach was employed by Fernández et al. (2003), who based their method on the integration of the atmospheric fluxes of moisture across regional boundaries. These authors clearly showed that the variability of precipitation within the Mediterranean Basin is closely related to the structure of the vertically integrated moisture transport fluxes inside the domain and at its borders.

In the belief that a Lagrangian approach can offer a more precise description of the trajectories of the air masses and their variability, compared to more traditional Eulerian techniques, the aim of the present study is to investigate the sources of moisture that are related to the wetter and drier seasonal conditions observed in the different regions that surround the Mediterranean Basin. In our methodology, "sources of moisture" are defined to be those regions that are crossed by the air masses during their transit towards the area of interest, in which the evaporation exceeds the precipitation. Moreover, all the air masses identified in the target region, even the nonprecipitating ones, are tracked back to their origins. A 5-yr analysis of the main sources and sinks of moisture that affect the Mediterranean Basin was reported previously by Nieto et al. (2010), which gives an overview of the annual mean patterns for different regions. Using the same trajectory data and target areas, the present work may be considered as an extension of Nieto et al. (2010), once we focus on the seasonal differences of the sources of moisture and on variations in drier and wetter periods for each target region considered. The robustness of our approach has been demonstrated previously in the successful application of the data and the methodology to climatological studies of sources of moisture in other regions, including the Sahel (Nieto et al., 2006), Iceland (Nieto et al., 2007), the Orinoco River basin (Nieto et al., 2008), the South American Monsoon System (Drumond et al., 2008), and the Iberian Peninsula (Gimeno et al., 2010).

The data, model and methodology are all described in Sect. 2. In Sect. 3, we show the results of the trajectory analyses. The main findings of our study are summarized in Sect. 4.

\section{Data and methodology}

In order to determine the sources of moisture, we made use of the Lagrangian particle dispersion model FLEXPART (Stohl et al., 2005). FLEXPART used global data from the meteorological analysis of the European Centre for MediumRange Weather Forecasts on model levels (White, 2002) to track different meteorological parameters for the entire 
atmosphere along individual trajectories. Because we are interested in atmospheric moisture, we used the specific humidity interpolated to the position in the trajectory at given points in time.

In order to identify the trajectory of each particle, the atmosphere was divided equally into a large number of particles at the start of the model run. These particles had a constant mass and were distributed homogeneously throughout the atmosphere according to the distribution of atmospheric mass. These particles were advected according to operational three-dimensional (3-D) ECMWF winds. In order to calculate both the grid-scale advection and the turbulent and convective transport of the particles, operational ECMWF data were also used as inputs to the model. The positions and specific humidity values $(q)$ were temporally interpolated from the ECMWF data, which were recorded every $6 \mathrm{~h}$. The increase $(e)$ and decrease $(p)$ in moisture along the trajectory could be calculated using the rate of change of $q$, i.e., $(e-p=m d q / \mathrm{d} t)$, where $m$ denotes the mass of a particle. By summation of $(e-p)$ for all the particles in an atmospheric column over a given area, it is possible to obtain the quantity $(E-P)$, where the surface freshwater flux $(E)$ represents evaporation and $(P)$ is the rate of precipitation per unit area. It is also possible to track $(E-P)$ for any specific region backwards in time along a number of trajectories, by choosing those particles that reach the target region at the time of interest.

In order to ensure an exact mass balance, vertical winds were calculated in the hybrid coordinates of the ECMWF model using spherical harmonics data during the data retrieval procedures at ECMWF. To account for turbulence, the FLEXPART model calculates the trajectory of the particles using analysed winds plus randomised motions. In the planetary boundary layer (PBL), these random motions are calculated by solving the Langevin equations for Gaussian turbulence (Stohl and Thomson, 1999). The height of the PBL may be determined using a combination of the Richardson number and the lifting parcel technique (Vogelezang and Holtslag, 1996); turbulence outside the PBL is assumed to be very small. Although global datasets cannot resolve individual convective cells, they can reproduce the large-scale effects of convection. FLEXPART has various options for the generation of particles and the material quantity represented by each. In our case, the atmosphere was homogeneously "filled" with particles, each representing a fraction of the total atmospheric mass. Particles were allowed to move (forwards or backwards in time) with the winds for the duration of the simulation. According to Stohl and James (2004, 2005), the limitations of the method are mainly concerned with the fact that the fluctuations in $q$ that occur along the individual trajectories also occur for numerical reasons (e.g., because of the interpolation of $q$ or because of errors in the trajectory concerned). Such noise is partly mitigated by the large numbers of particles present in a given atmospheric column.

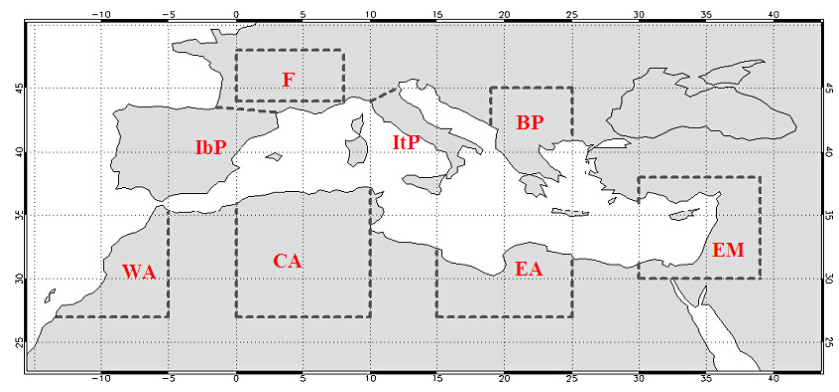

Fig. 1. The selected subregions of the Mediterranean Basin used to calculate the backward trajectories of $(E-P)$. The regions indicated in red are: Iberian Peninsula (IbP), France (F), Italian Peninsula (ItP), Balkan Peninsula (BP), Eastern Mediterranean (EM) and Western, Central and Eastern North Africa (WA, CA and EA, respectively).

We herein describe our use of the tracks of 1.3 million particles over a 5-yr period (March 2000-February 2005), which were computed using the ECMWF operational analysis that was available at 6 hourly intervals (00:00, 06:00, 12:00 and 18:00 UTC) at a resolution of $1^{\circ} \times 1^{\circ}$ in latitude and longitude for all 60 vertical model levels. Analysis of the $(E-P)$ retrotrajectories was performed for eight subregions within the extended Mediterranean Basin $\left(50^{\circ} \mathrm{N}-28^{\circ} \mathrm{N}\right.$ lat, $10^{\circ} \mathrm{W}-$ $40^{\circ} \mathrm{E}$ lon), namely the Iberian Peninsula (IbP), France (F), the Italian Peninsula (ItP), the Balkan Peninsula (BP), the Eastern Mediterranean (EM) and three regions of Western, Central and Eastern North Africa (WA, CA and EA, respectively) (as shown in capital letters in Fig. 1). These subregions coincide with the areas chosen by Nieto et al. (2010). Following the recommendations of Stohl and James (2005) and Sodemann et al. (2008a), we limited the transport times to 10 days. According to these authors, 10 days is the average time for which water vapour resides in the atmosphere (Numaguti, 1999), and it is also a period of time over which the trajectories can be considered to be relatively accurate (Stohl, 1998).

In order to identify, for each season, drier and wetter years in the period under consideration, we used data from the Global Precipitation Climatology Project (GPCP) Version 2 (Huffman et al., 2001), which were available at daily intervals and at a horizontal resolution of $1^{\circ}$. We calculated the seasonal precipitation rate, averaged over each of the eight subregions, throughout the period from March 2000 to February 2005 inclusive, taking the boreal seasons to be MAM (Spring), JJA (Summer), SON (Autumn) and DJF (Winter). For each season and each region, we selected those years that had the highest and lowest precipitation rates, hereafter termed the wetter and drier years. To assess the potential implications of changes in the source of moisture (in location and/or intensity) for a given target region, we also obtained the seasonally averaged values of $(E-P)$ for these years. It is important to stress that all the 

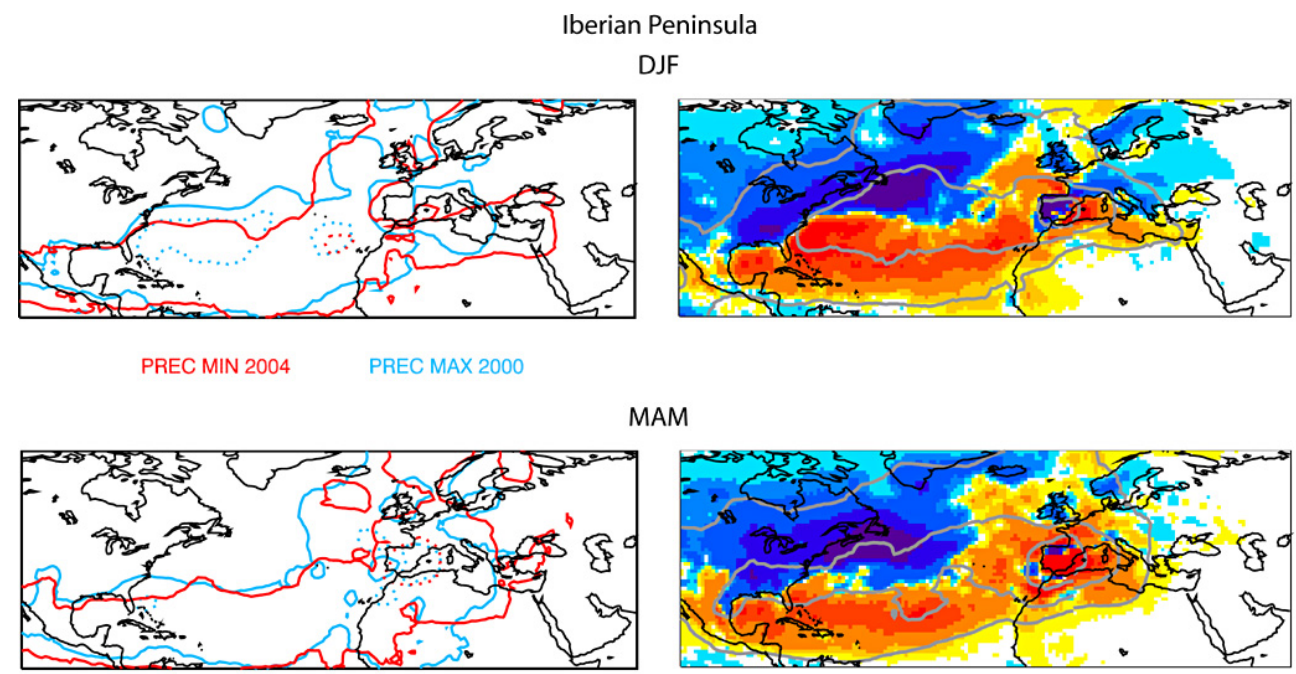

PREC MIN $2003 \quad$ PREC MAX 2000

JJA
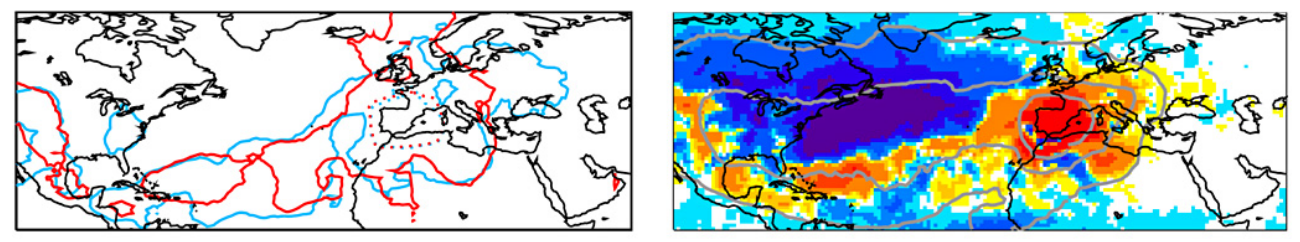

PREC MIN 2001 PREC MAX 2002

SON

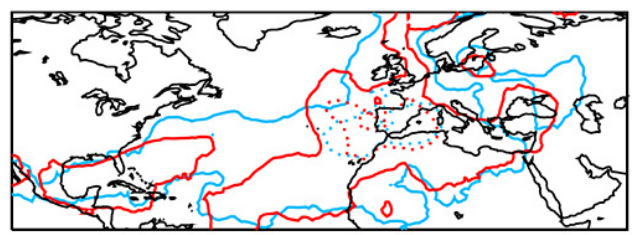

PREC MIN 2004

PREC MAX 2003
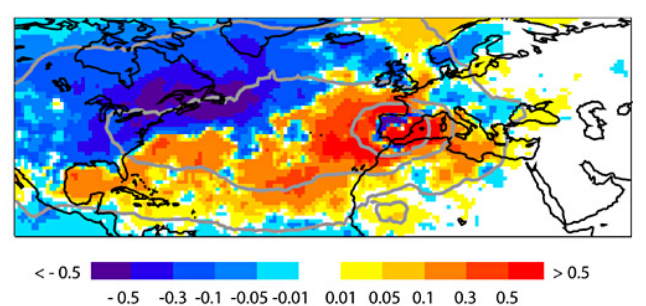

Scale $\left(\times 10^{-7} \mathrm{~mm} /\right.$ day $\left./ \mathrm{km}^{2}\right)$

Fig. 2. (left-hand panels): Seasonal backward analysis for the Iberian Peninsula (IbP) using 10-day retrointegrated average values of ( $E-P$ ). The values were normalized by the area of the target region $\left(618945 \mathrm{~km}^{2}\right)$ showing contours of $0.01 \times 10^{-7} \mathrm{~mm} \mathrm{day}^{-1} \mathrm{~km}^{-2}(\mathrm{solid}$ lines) and $0.5 \times 10^{-7} \mathrm{~mm} \mathrm{day}^{-1} \mathrm{~km}^{-2}$ (dotted line) observed for the selected wetter (blue lines) and drier (red lines) years (indicated below each figure); (right-hand panels): seasonal 10-day retro-integrated average values of $(E-P)$ normalized by the area of the target region for 2000-2004 (shaded, by $10^{-7} \mathrm{~mm} \mathrm{day}^{-1} \mathrm{~km}^{-2}$ ) and variance (grey contour lines of $0.01,0.1$ and $0.5 \times 10^{-14} \mathrm{~mm}^{2} \mathrm{day}^{-2} \mathrm{~km}^{-4}$ ).

air masses identified in the target region during the selected periods, even the nonprecipitating ones, were tracked backwards and included in our analysis.

Herein, we present the values of $(E-P)$ integrated over a 10-day period (from the first to the tenth day of the trajectory) and normalized by the respective target area in order to facilitate a comparative analysis of the regional results. The normalization is necessary because the number of particles selected increases according to the size of the target region, and as a consequence the magnitude of the values of $(E-P)$ integrated for an atmospheric column over a given area is higher for larger target regions. The areas of the target regions considered in our numerical approximations are shown in the legends of the respective figures. The resulting fields can be interpreted to be the net gains or losses of moisture in a region during the previous 10 days and we can, thereby, identify the sources of moisture to be those regions where evaporation exceeded precipitation over the period. Nevertheless, part of the uptake of moisture from the source regions can fall as precipitation along the trajectories of the air masses as they move towards the target area. In the same way, regions that have a net negative value of $(E-P)$ can still act as significant sources of moisture for the target area on some of the 10 days under consideration here. The 
Table 1. Seasonal mean precipitation rates $\left(\mathrm{mm} \mathrm{day}^{-1}\right)$ averaged for each of the target regions indicated in Fig. 1. For each season and region, the highest and the lowest values are highlighted in blue and red, respectively.

\begin{tabular}{clrrrrrrrr}
\hline Year & Season & IbP & F & ItP & BP & EM & EA & CA & WA \\
\hline 2000 & MAM & 2.884 & 2.904 & 2.050 & 1.561 & 0.943 & 0.093 & 0.407 & 0.459 \\
2000 & JJA & 0.698 & 2.848 & 1.041 & 0.839 & 0.104 & 0.002 & 0.099 & 0.060 \\
2000 & SON & 2.791 & 4.507 & 3.677 & 2.324 & 0.773 & 0.130 & 0.558 & 0.353 \\
$2000-2001$ & DJF & 4.487 & 2.907 & 3.557 & 2.638 & 1.587 & 0.381 & 0.519 & 0.968 \\
2001 & MAM & 2.622 & 4.485 & 2.339 & 2.657 & 1.169 & 0.061 & 0.258 & 0.263 \\
2001 & JJA & 0.668 & 2.850 & 0.716 & 1.652 & 0.075 & 0.004 & 0.054 & 0.062 \\
2001 & SON & 2.221 & 2.701 & 2.426 & 2.330 & 1.140 & 0.271 & 0.437 & 0.268 \\
$2001-2002$ & DJF & 1.448 & 2.257 & 1.862 & 1.965 & 2.458 & 0.764 & 0.322 & 0.769 \\
2002 & MAM & 2.488 & 2.566 & 2.146 & 2.416 & 1.160 & 0.174 & 0.403 & 1.232 \\
2002 & JJA & 1.067 & 3.029 & 2.152 & 2.782 & 0.238 & 0.007 & 0.264 & 0.072 \\
2002 & SON & 3.159 & 4.485 & 3.245 & 3.459 & 0.692 & 0.216 & 0.588 & 1.033 \\
$2002-2003$ & DJF & 3.606 & 2.807 & 4.185 & 4.155 & 2.436 & 0.435 & 0.987 & 0.816 \\
2003 & MAM & 1.901 & 1.807 & 1.274 & 1.703 & 1.253 & 0.317 & 0.426 & 0.568 \\
2003 & JJA & 0.735 & 1.847 & 1.239 & 1.249 & 0.092 & 0.029 & 0.116 & 0.251 \\
2003 & SON & 3.466 & 3.360 & 3.884 & 3.297 & 0.705 & 0.092 & 0.690 & 1.194 \\
$2003-2004$ & DJF & 2.251 & 3.321 & 3.440 & 3.234 & 2.674 & 0.275 & 0.648 & 0.804 \\
2004 & MAM & 2.592 & 2.449 & 3.085 & 2.442 & 0.599 & 0.167 & 0.912 & 0.645 \\
2004 & JJA & 0.779 & 2.737 & 1.391 & 2.215 & 0.117 & 0.020 & 0.245 & 0.123 \\
2004 & SON & 1.871 & 2.508 & 3.739 & 2.884 & 1.024 & 0.167 & 0.564 & 0.527 \\
$2004-2005$ & DJF & 1.381 & 2.157 & 4.395 & 3.648 & 1.568 & 0.756 & 0.755 & 0.757 \\
\hline
\end{tabular}

uptake and loss of moisture along the trajectories could be investigated in detail by means of a daily analysis of $(E-P)$ (Stohl and James, 2005), but we believe that the inclusion of this kind of analysis would not add that much to our results, given our goal of a qualitative overview of the variations in the spatial structure and magnitude of the sources of moisture in different target areas under specific climatological conditions. The interannual variability of $(E-P)$ can be evaluated by means of its variance.

\section{Results}

Table 1 shows the seasonal precipitation rates averaged for each of the eight subregions, and shows the lowest (highest) values in red (blue) for each season and subregion over the period. The results in Table 1 allow us to identify the spatial extent of some periods selected, for example, the predominance of the drought conditions that occurred during 2001 over North Africa and Italy in particular, as well as the wet summer of 2002 that extended over almost the entire Mediterranean Basin. The lower seasonal values observed over IbP and F during the autumn of 2004 and the following winter agree with the findings of other authors who identified the hydrological year 2004-2005 in the Iberian Peninsula to be the driest since global volumes of precipitation were first recorded (Garcia-Herrera et al., 2007; Santos et al., 2007). This particular episode was also investigated by Gimeno et al. (2010), who studied the contribution to precipitation in
IbP of the Tropical Atlantic source of moisture under dry (2004/2005) and wetter (2000/2001) winter conditions using the same methodology as we have adopted here. The temporal persistence of some episodes was also observed, as the case of the drier (2000) and the wetter (2002) years in BP. We believe that these special cases merit further investigation.

Figure 2 shows the results of our analysis of the sources of moisture for the drier and wetter years for IbP (Fig. 2, left-hand panel), together with the 5-yr average and variance of the seasonal fields of $(E-P)$ (Fig. 2, right-hand panel). Because a more detailed climatological analysis of the main annual sources and sinks of moisture has already been performed for all the regions concerned by $\mathrm{Ni}$ eto et al. (2010), the focus of our discussion here is on a seasonal analysis and comparison of the main sources of moisture during the years selected. The left-hand panels show the $0.01 \times 10^{-7} \mathrm{~mm} \mathrm{day}^{-1} \mathrm{~km}^{-2}$ (solid lines) and $0.5 \times 10^{-7} \mathrm{~mm} \mathrm{day}^{-1} \mathrm{~km}^{-2}$ (dotted lines) contours for $(E-$ $P$ ) integrated during the years selected (indicated at the bottom of each figure). The blue lines correspond to the wetter year and the red lines to the drier one. These thresholds were selected for the contour lines because they correspond to the lowest and the highest positive thresholds plotted in the 5-yr average values of $(E-P)$, hence, elucidating the differences from the "climatological" fields. The 5-yr seasonal average and variance (Fig. 2, right-hand panel) shows the contribution of the Mediterranean Sea and of a region that extends from the Atlantic western European coast to the 

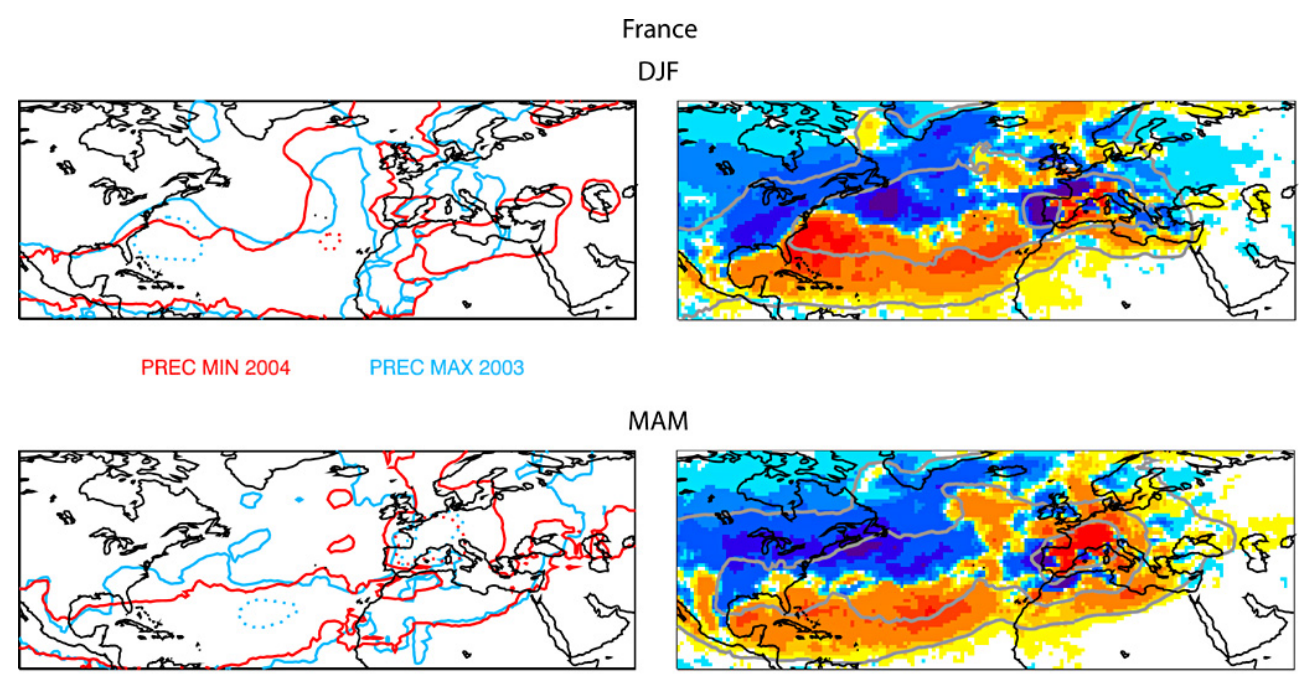

PREC MIN $2003 \quad$ PREC MAX 2001

JJA
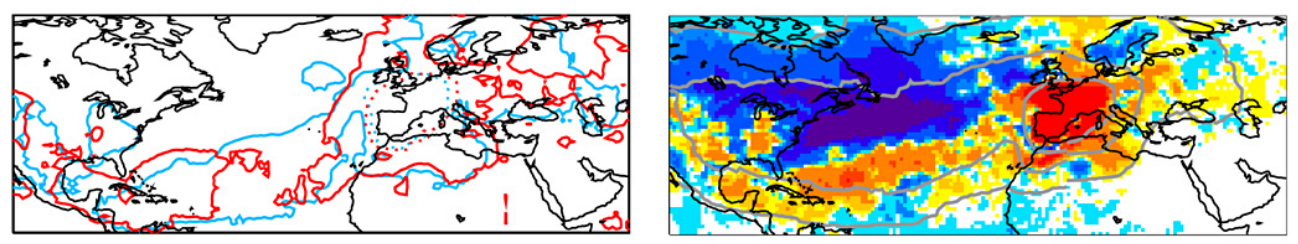

PREC MIN 2003

PREC MAX 2002

SON

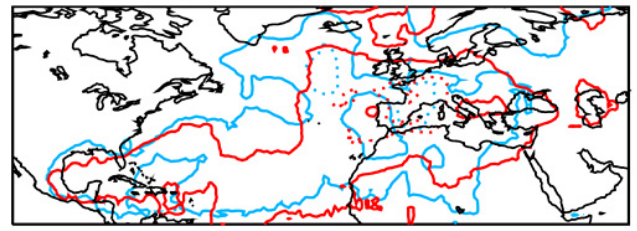

PREC MIN 2004

PREC MAX 2000
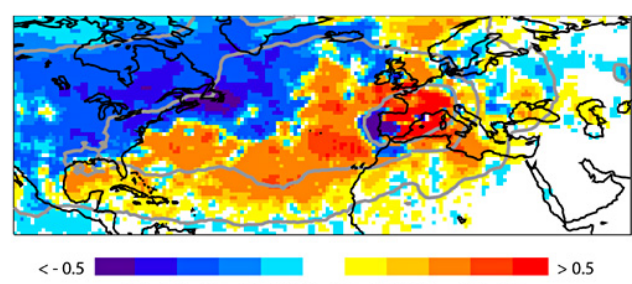

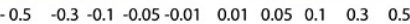

Scale $\left(\times 10^{-7} \mathrm{~mm} /\right.$ day $\left./ \mathrm{km}^{2}\right)$

Fig. 3. As Fig. 2, but for France (F), considering its equivalent area as $277264 \mathrm{~km}^{2}$.

subtropical-tropical North Atlantic (STNA) (the red colours indicate $E-P>0$ ) for IbP throughout the year. The contribution from the STNA is only lower during JJA. An analysis of the variance of $(E-P)$ (grey contour lines of 0.01 , 0.1 and $0.5 \times 10^{-14} \mathrm{~mm}^{2}$ day $^{-2} \mathrm{~km}^{-4}$ ) indicates that the areas that show higher interannual variations extend over the Iberian Peninsula and the North Atlantic and, more precisely, lie close to the interface between the positive and negative climatological values of $(E-P)$. The importance of the Atlantic source and its characteristics has already been discussed in a detailed climatological analysis of the Iberian Peninsula presented by Gimeno et al. (2010). Comparing the wetter and drier years (Fig. 2, left-hand panel) it appears that the main differences lie in the spatial extension and/or the intensity of the Atlantic source, which is predominantly larger during the wetter periods.

The contribution from the Atlantic source is also observed for subregion F (Fig. 3). The seasonal evolution of the "climatological" fields (the 5-yr averages, Fig. 3, right-hand panels) indicates the importance of Western Europe as a source of moisture for France throughout the year, except during DJF when the results suggest that the main contribution is from the STNA. The analysis of the variance of $(E-P)$ indicates that those areas that have higher interannual variations extend over Western Europe and lie close to the interface between the positive and negative climatological values of $(E-P)$ observed in the North Atlantic. Comparing the wetter and drier years (Fig. 3, left-hand panel), the contribution 

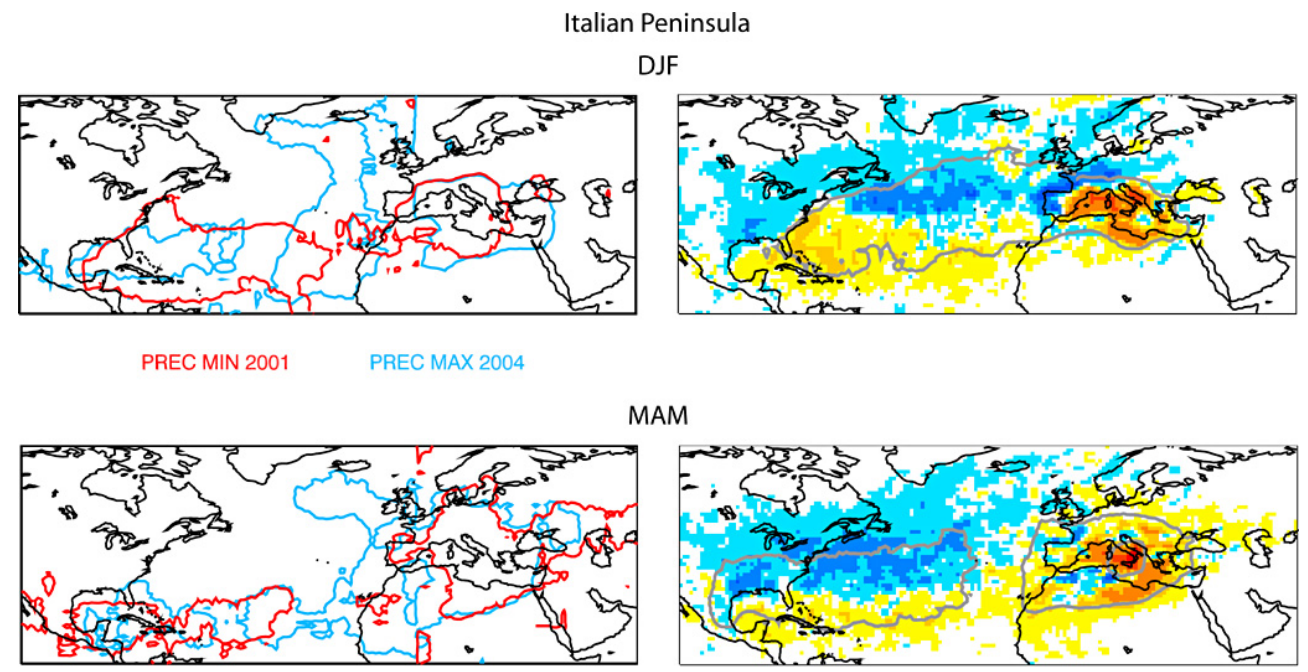

PREC MIN $2003 \quad$ PREC MAX 2004

JJA
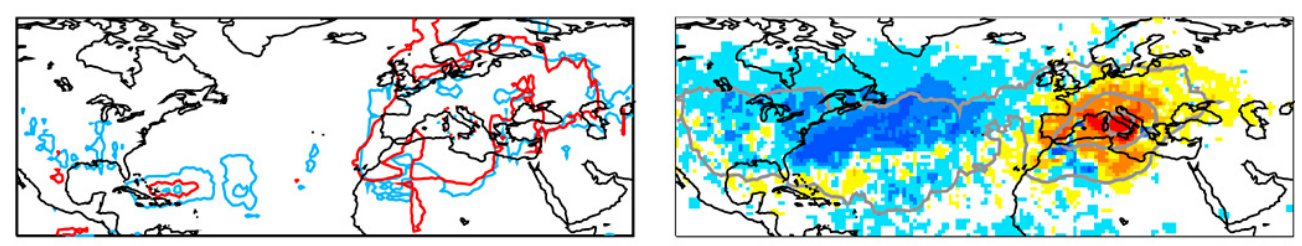

PREC MIN $2001 \quad$ PREC MAX 2002

SON

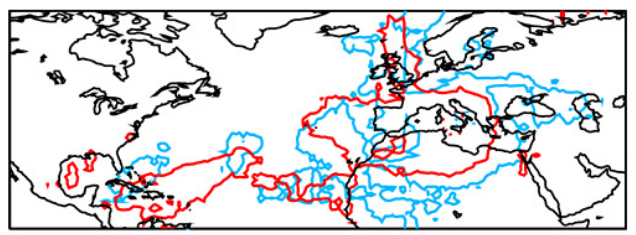

PREC MIN 2001

PREC MAX 2003

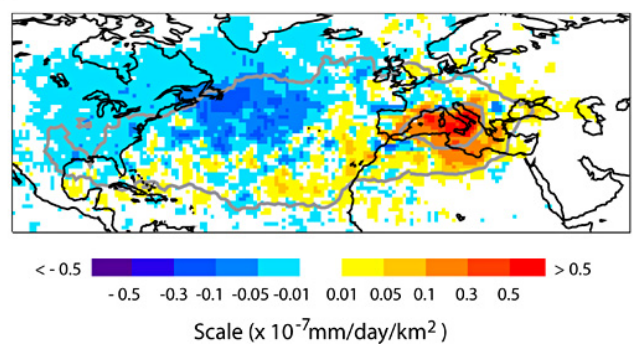

Fig. 4. As Fig. 2, but for the Italian Peninsula (ItP), considering its equivalent area as $205507 \mathrm{~km}^{2}$.

from the STNA and Western Europe is even greater during the wetter periods.

The results obtained for France can be compared with the detailed climatological study of Sodemann and Subler (2010) of the sources of moisture for Alpine precipitation. Although their target area is slightly different and their Lagrangian methodology considers the air masses that precipitate over the Alps in a different period (1995-2002), they were nevertheless able to identify the contributions from the oceanic areas of the North Atlantic, the Mediterranean Sea and the North and Baltic Seas, apart from that from the European land surface. The strong seasonal variability of the influence of the sources of moisture is also evident, with the North Atlantic source being dominant during winter and the Central European land areas being dominant in summer. They identify the interannual variability with respect to the location of the moisture sources in the North Atlantic, as well as the importance of recycling of precipitation during the summer.

Figure 4 shows our results for the Italian Peninsula. From the average fields shown in the right-hand panels, it is possible to note the predominance of Southern Europe and the Mediterranean region as sources of moisture throughout the year. The Caribbean Sea is a source during DJF, but the negative values over Western Europe (indicating that this is a region where a net of moisture losses occur during the 10day period) suggest that part of the moisture carried by the air masses from the Atlantic could precipitate there before reaching ItP, implying that this potential source is less important in providing moisture for the region. Southern Europe 

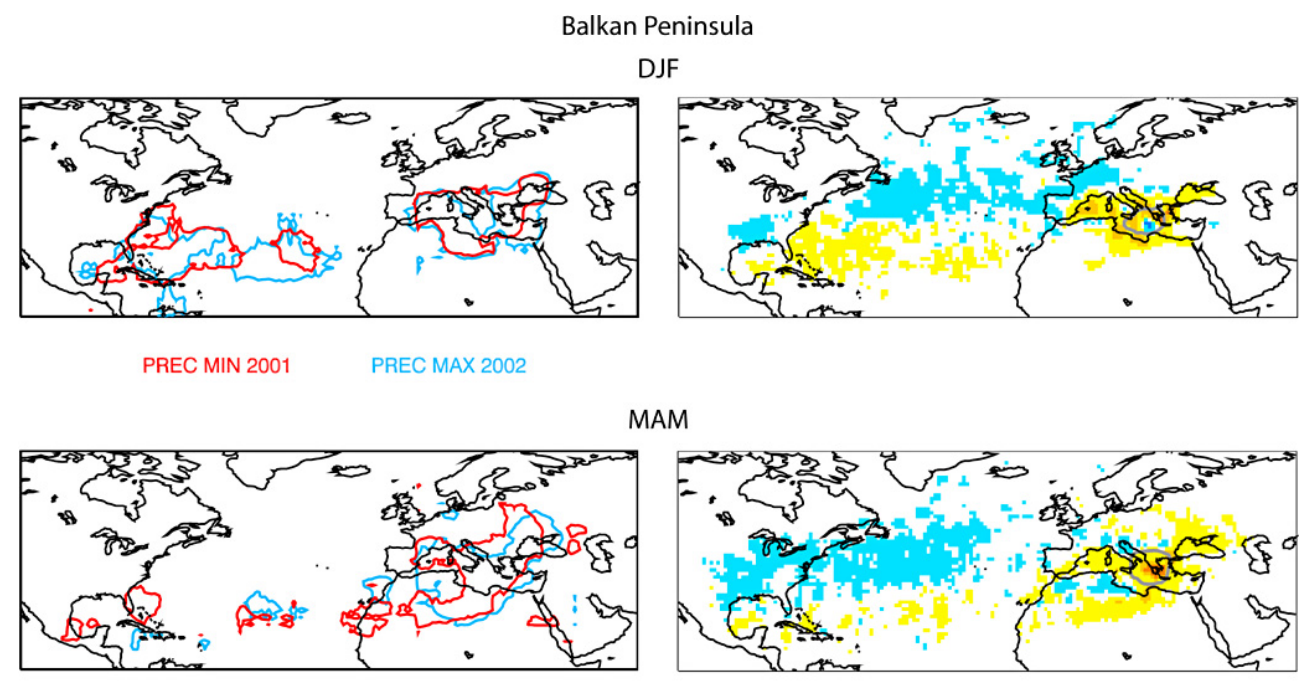

PREC MIN $2000 \quad$ PREC MAX 2001

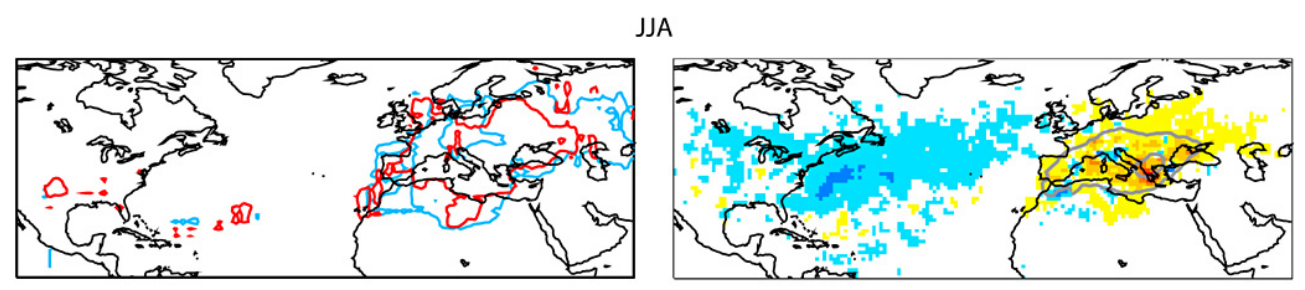

PREC MIN $2000 \quad$ PREC MAX 2002

SON
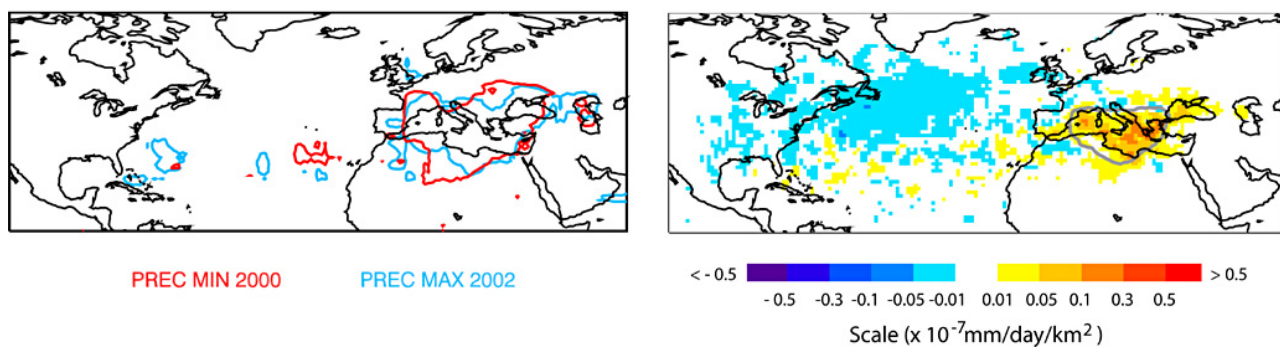

Fig. 5. As Fig. 2, but for the Balkan Peninsula (BP), considering its equivalent area as $353643 \mathrm{~km}^{2}$.

is also the region that has the highest interannual variation of $(E-P)$ according to the analysis of variance (right-hand panels of Fig. 4). Comparing the wetter and drier periods (Fig. 4, left panels), it may be seen that the intensity and/or spatial extension of the continental source is higher during wetter conditions, as well as the areal extension of the eastern Atlantic source.

The Mediterranean Basin is also the most prominent source of moisture for BP (Fig. 5, right-hand panels), except during JJA when the spatial structure of the source expands towards Europe. When comparing between wetter and drier conditions, it is interesting to note that the structure of the sources of moisture is quite similar, expanding slightly more during wetter conditions (Fig. 5, left-hand panels), and the higher interannual variations are observed over the target region during JJA.

The source of moisture for EM lies mainly in the adjacent Mediterranean Sea, and it is more intense and presents higher interannual variations during JJA (Fig. 6, right-hand panels). There was a westerly extent of the source during wetter years, except in JJA (Fig. 6, left-hand panels).

The Mediterranean Sea is one of the most prominent sources of moisture for subregion EA throughout the year and it expands its domain towards Europe during JJA (the driest season as per Table 1) (see Fig. 7, right-hand panel). The central Mediterranean Basin is also the area that has the highest interannual variations of $(E-P)$ according to the analysis of variance, particularly during JJA (grey contour lines, 
DJF

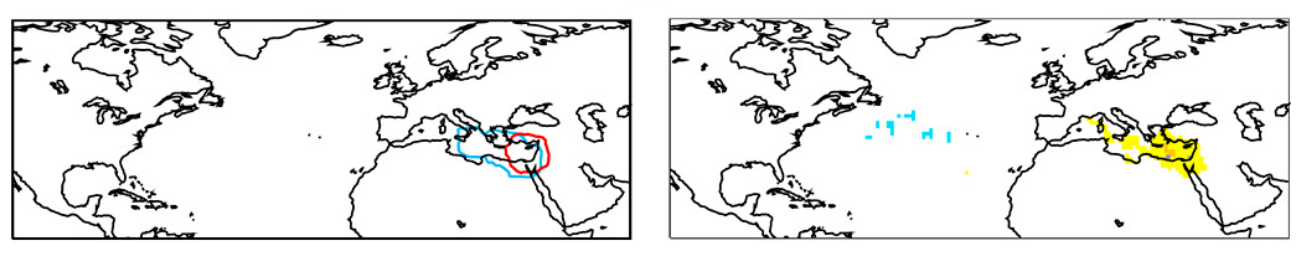

PREC MIN $2004 \quad$ PREC MAX 2003

MAM

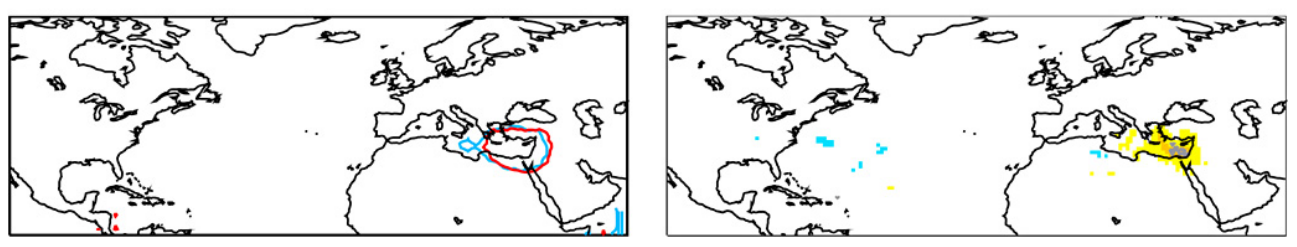

PREC MIN $2004 \quad$ PREC MAX 2003

JJA

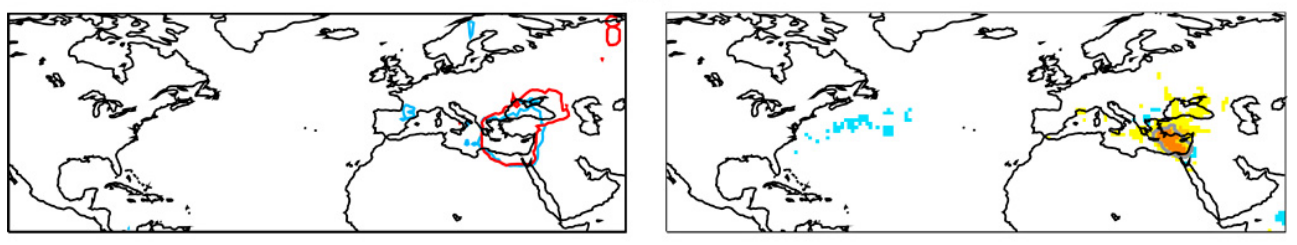

PREC MIN $2001 \quad$ PREC MAX 2002

SON

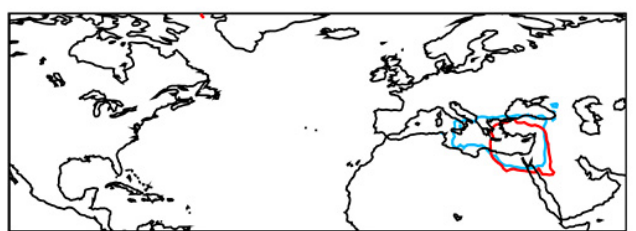

PREC MIN 2002

PREC MAX 2001

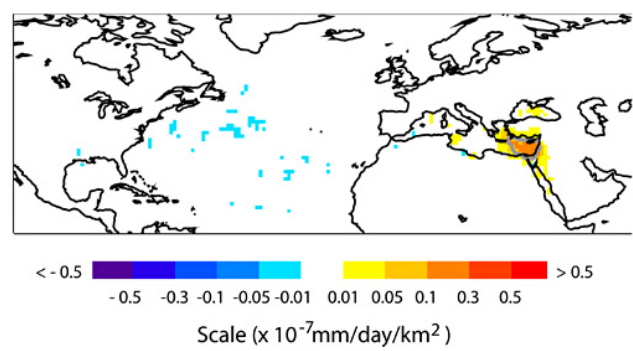

Fig. 6. As Fig. 2, but for the Eastern Mediterranean subregion (EM), considering its equivalent area as $504492 \mathrm{~km}^{2}$.

Fig. 7 right-hand panels). Comparing wetter and drier conditions (Fig. 7, left-hand panel), the results show that the spatial extent and intensity of the source of moisture are slightly larger for wetter years.

As for $\mathrm{IbP}$ and $\mathrm{F}$, the results indicate a moisture contribution from STNA for CA that mainly applies in DJF and MAM (Fig. 8, right-hand panels). In addition, the contributions from the Mediterranean Basin and North Africa may be seen throughout the year. An analysis of the variance of $(E-P)$ (Fig. 8 right-hand panels, grey contour lines) indicates that the Mediterranean and the North Atlantic are the regions that had the highest interannual variations. One of the main differences between wetter and drier conditions (Fig. 8, left-hand panel) is the expansion and intensification of the source over the Atlantic during DJF in the wetter year. It is interesting to note that all the drier seasons selected refer to the period March 2001-February 2002. There is a larger spatial extension of the source towards the north Atlantic Ocean during MAM in the wetter year. During JJA, the driest season for CA according to the period considered in Table 1, the spatial extent of the source is reduced to Europe, the Mediterranean Basin and North Africa, and its south-westward extension during wetter conditions can be clearly seen. The north-eastward and southward expansion of this source may also be seen during SON in the wetter year. In contrast with $\mathrm{CA}$, the moisture contribution for WA is more local and expands its domain towards the Iberian Peninsula and the adjacent oceanic regions during MAM and JJA (Fig. 9, righthand panels). The target region also had the highest interannual variations of $(E-P)$ according to the analysis of the 

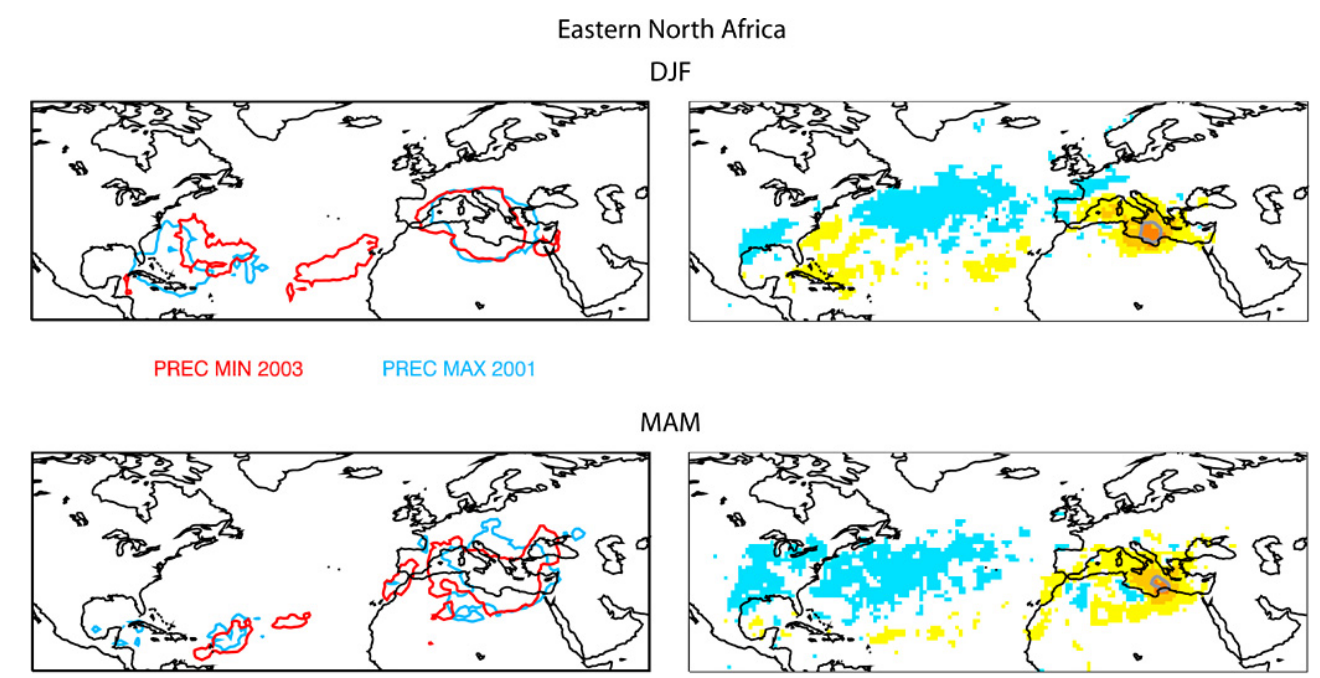

PREC MIN $2001 \quad$ PREC MAX 2003

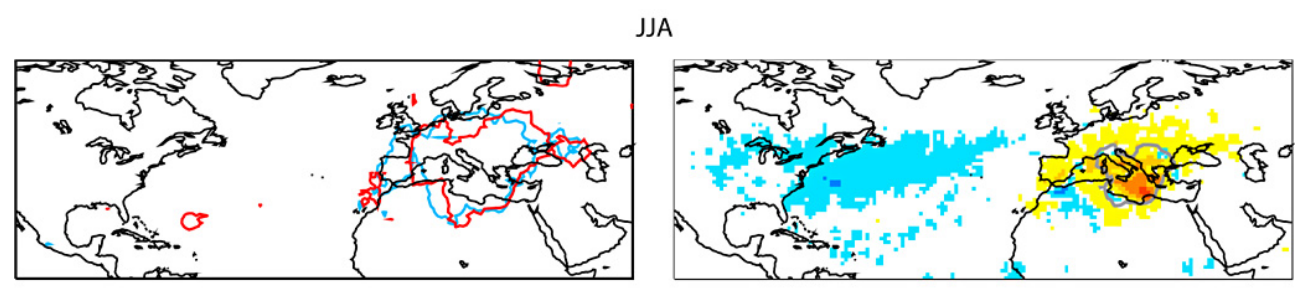

PREC MIN $2000 \quad$ PREC MAX 2003

SON

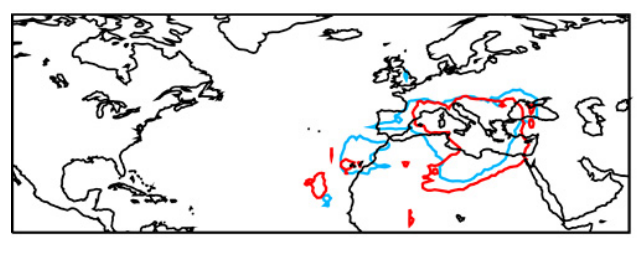

PREC MIN $2003 \quad$ PREC MAX 2001

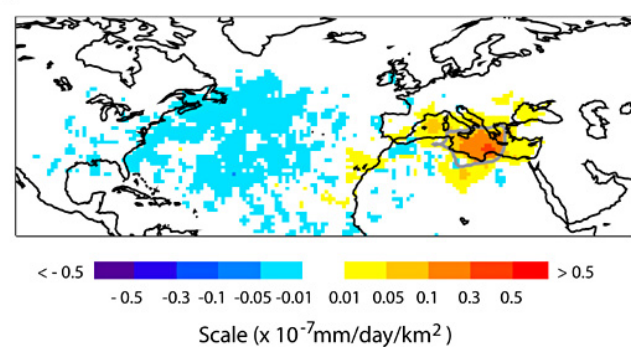

Fig. 7. As Fig. 2, but for the Eastern North Africa subregion (EA), considering its equivalent area as $518997 \mathrm{~km}^{2}$.

variance (grey contour lines, Fig. 9 right-hand panels), particularly during JJA. Comparing wetter and drier conditions (Fig. 9, left-hand panels), it appears that there is a spatial expansion of the source in wetter years towards the adjacent Atlantic area.

\section{Conclusions}

Using data obtained from the Lagrangian FLEXPART model for the period 2000-2005, we have investigated variations in the sources of moisture related to drier and wetter seasonal conditions in different regions around the Mediterranean Basin. We considered a standard 5-yr period in which the strong extreme phases of the major modes of climate variability at the global climate scale (e.g., ENSO or NAO) were absent.

We carried out an analysis of the retrotrajectories of ( $E-$ $P$ ) for eight subregions within the extended Mediterranean Basin $\left(50^{\circ} \mathrm{N}-28^{\circ} \mathrm{N}\right.$ lat, $10^{\circ} \mathrm{W}-40^{\circ} \mathrm{E}$ lon $)$, and limited the transport times to 10 days. The selected subregions were the Iberian Peninsula (IbP), France (F), the Italian Peninsula (ItP), the Balkan Peninsula (BP), Eastern Mediterranean (EM) and Western, Central and Eastern North Africa (WA, CA and EA). It is important to note that in our methodology, we define "sources of moisture" to be those regions crossed by air masses that are in transit towards the target area and where there is a predominance of evaporation over precipitation. 

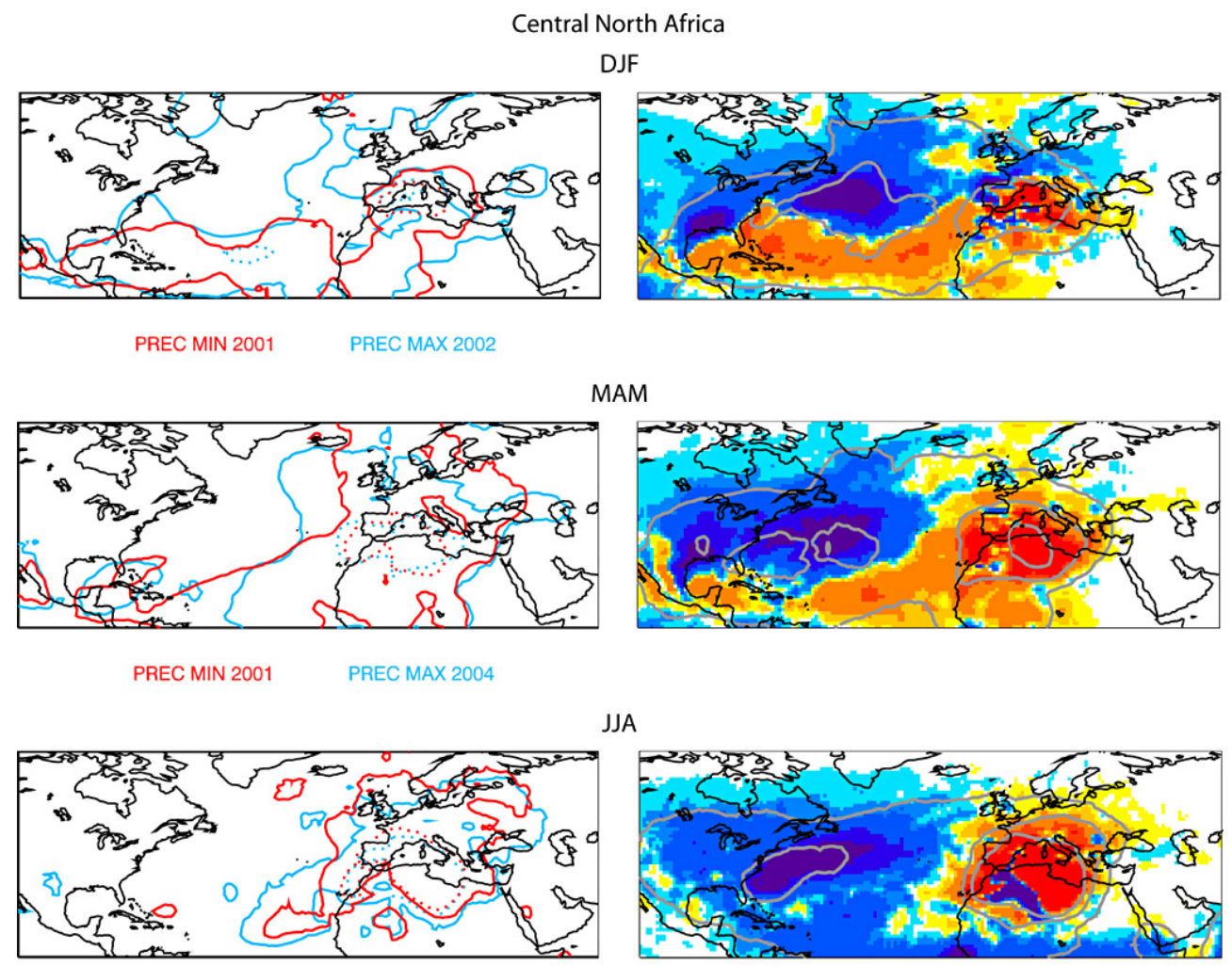

JJA

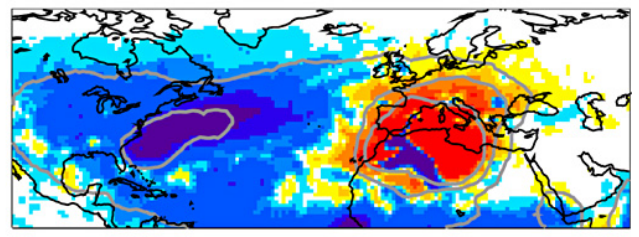

PREC MIN $2001 \quad$ PREC MAX 2002

SON

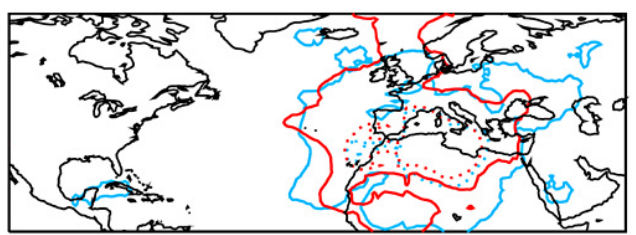

PREC MIN 2001

PREC MAX 2003

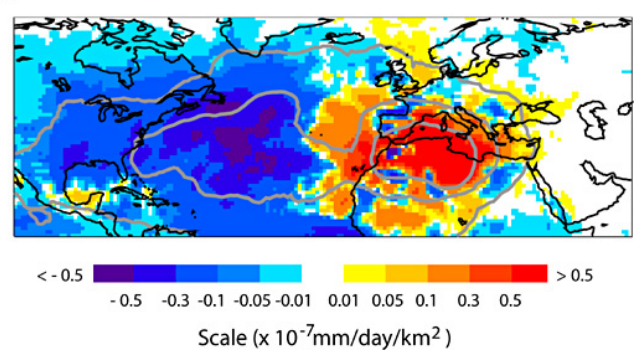

Fig. 8. As Fig. 2, but for the Central North Africa subregion (CA), considering its equivalent area as $1052890 \mathrm{~km}^{2}$.

For each season and subregion, we selected those years that presented the highest and lowest seasonal precipitation rates for the period 2000-2005 and, thereafter, referred to these as wetter and drier years, respectively. To assess the potential implications of changes in sources of moisture (location and/or intensity), we compared the 10-day integrated values of $(E-P)$ associated with the years selected. All $(E-P)$ fields were normalized by the respective target area in order to facilitate a comparative analysis of the regional results.

The contribution of the north Atlantic (mainly from subtropical latitudes and the eastern North Atlantic region) as a moisture source is apparent for the Iberian Peninsula, France and Central Africa. During JJA, the contribution from the Atlantic reduces and the sources of moisture are mostly located over continental areas and over the Mediterranean Basin. The results suggest that the larger extent and the higher intensity of the Atlantic source during wetter conditions is one of the main differences between the wetter and drier years.

The moisture sources for the Italian and Balkan Peninsulas are centred on the Mediterranean Basin, and extend towards Europe during JJA. In general, the sources of moisture are more intense and greater in extent during wetter conditions. For ItP, the source also expands towards eastern north Atlantic Ocean in wetter years, except during JJA. The Mediterranean Basin is also a source of moisture for Eastern North Africa and the areal domain of this source extends towards Europe during JJA. For the Eastern Mediterranean subregion, the source of moisture is located over the eastern basin and the results indicate a small westward expansion during wetter 

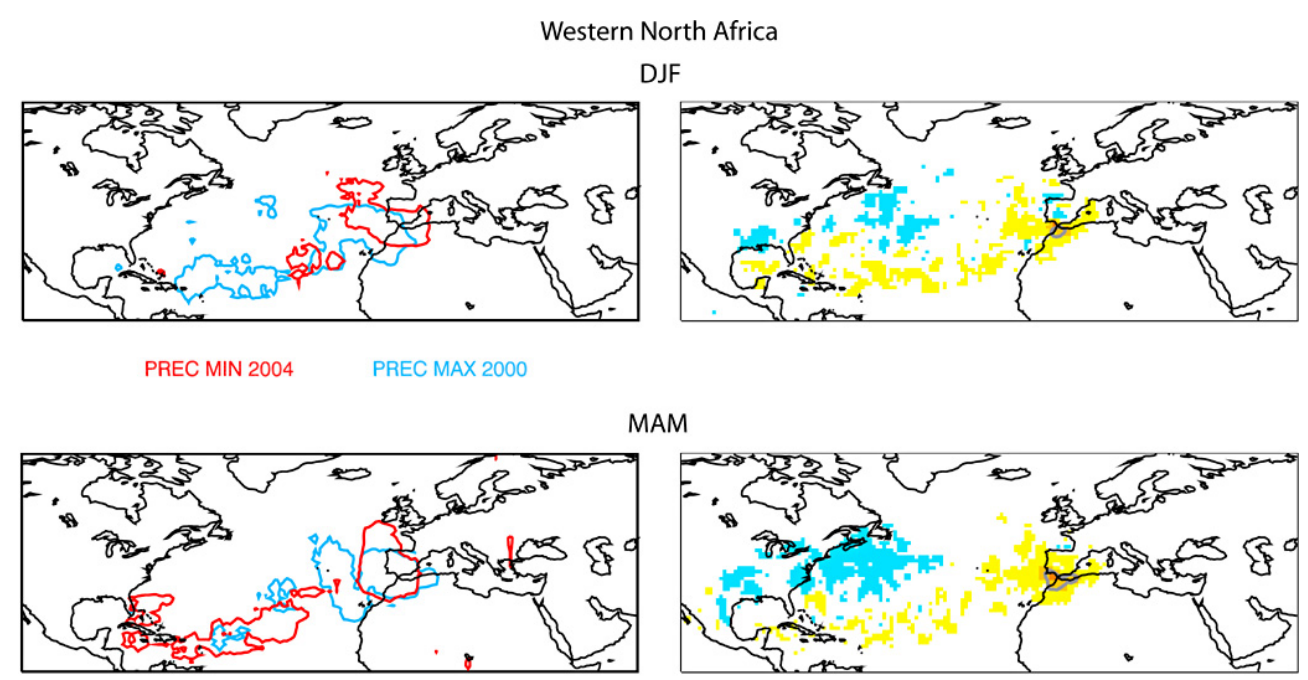

PREC MIN $2001 \quad$ PREC MAX 2002

JJA
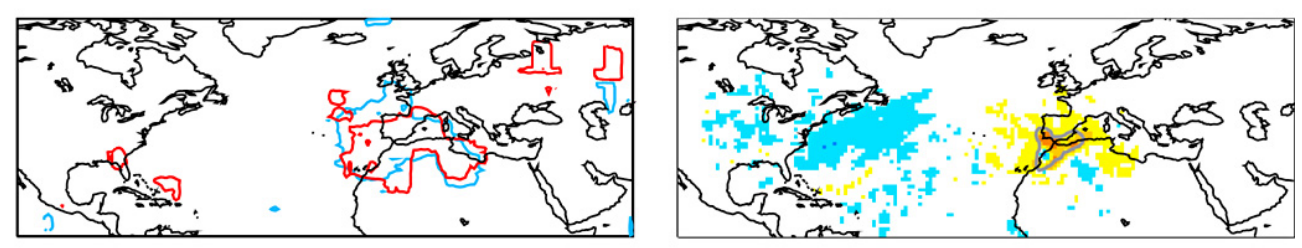

PREC MIN $2000 \quad$ PREC MAX 2003

SON

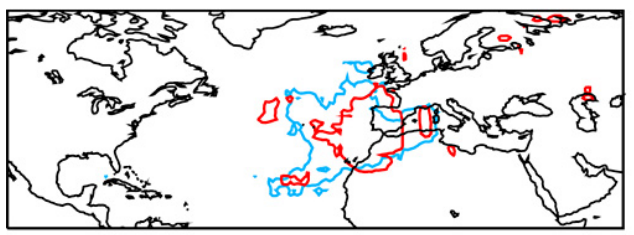

PREC MIN 2001

PREC MAX 2003

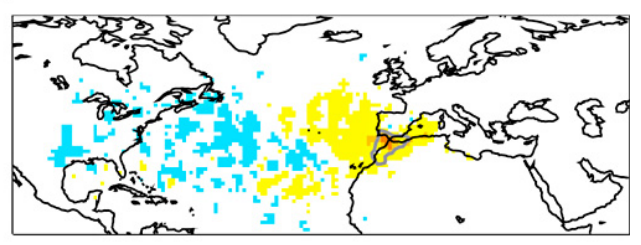

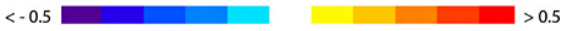

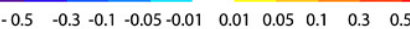

Scale ( $\left.\times 10^{-7} \mathrm{~mm} / \mathrm{day} / \mathrm{km}^{2}\right)$

Fig. 9. As Fig. 2, but for the Western North Africa subregion (WA), considering its equivalent area as $439845 \mathrm{~km}^{2}$.

conditions, except in JJA. A local source of moisture centred over the Gibraltar Strait was found for Western North Africa. Comparing wetter and drier conditions, it appears that there is a spatial expansion of the source in wetter years towards the adjacent Atlantic area.

The results suggest that in most of the selected years, the sources of moisture were larger and/or more intense during wetter conditions. It is important to stress that the whole of the analysis of the contrasts between wetter and drier conditions was carried out using a qualitative comparison of the results concerned, without quantifying variation in the contribution from the sources of moisture. The availability of only short period of data limits both the selection of episodes and the application of any statistical evaluation. Moreover, the short period covered by our study does not allow exploring the various regimes leading to wetter/drier conditions over the different parts of the Mediterranean region convincingly. The scope of our study was, therefore, to use case studies to provide an overview of the regional characteristics of the Mediterranean Sea, and to suggest that differences between drier and wetter years could be related to some variations in the sources of moisture. We, nevertheless, argue that the use of a longer period of data would be necessary for a more conclusive discussion. In an attempt to address this issue, a 40-yr FLEXPART experiment is being conducted, which should allow studies to take place at a climatological scale, together with a more meaningful statistical evaluation of the results. 
Acknowledgements. We, hereby, thank Andreas Stohl for providing the data on the trajectories. The work described herein was supported by the Spanish Ministry of Science and Inovation (MCINN) under Grant nos. CGL2008-05968-C02-02 and CGL2008-05968-C02-01 (MSM). A. Drumond and R. Nieto also received some support from the EU MedClivar Programme. L. Gimeno and R. Nieto received some support from a PortugueseSpanish integrated initiative funded by CRUP (E-16/2008) and MCYT (HP2007-0064). This work was partially supported by Xunta de Galicia under Programa de Consolidación e Estruturación de Unidades deInvestigación (Grupos de Referencia Competitiva) funded by European Regional Development Fund (FEDER). The constructive comments of Piero Lionello, Heini Wernli and the anonymous reviewer are gratefully acknowledged.

Edited by: P. Lionello

Reviewed by: H. Wernli and another anonymous referee

\section{References}

Arpe, K. and Roeckner, E.: Simulation of the hydrologic cycle over Europe: Model validation and impacts of increasing greenhouse gases, Adv. Water Resour., 23, 105-119, 1999.

Bethouk, J. P. and Gentili, B.: Functioning of the Mediterranean Sea: Past and present changes related to freshwater input and climatic changes, J. Marine Syst., 20, 33-47, 1999.

Bosilovich, M. G., Sud, Y. C., Schubert, S. D., and Walker, G. K. : Numerical simulation of the large-scale North American monsoon water sources, J. Geophys. Res., 108, 8614, doi:10.1029/ 2002JD003095, 2003.

Brubaker, K. L., Entekhabi, D., and Eagleson, P.: Estimation of Continental Precipitation Recycling, J. Climate, 6, 1077-1089, 1993.

Chen, T. C., Pfaendtner, J., and Weng, S. P.: Aspects of the hydrological cycle of the ocean-atmosphere system, J. Phys. Oceanogr., 24, 1827-1833, 1994.

Crimp, S. J. and Mason, S. J.: The extreme precipitation event of 11 to 16 February 1996 over South Africa, Meteorol. Atmos. Phys., 70, 29-42, 1999.

Drumond, A., Nieto, R., Gimeno, L., and Ambrizzi, T.: A Lagrangian identification of major sources of moisture over Central Brazil and La Plata Basin, J. Geophys. Res., 113, D14128, doi:10.1029/2007JD009547, 2008.

Eltahir, E. and Bras, R. L.: Precipitation recycling, Rev. Geophys., 34, 367-378, 1996.

Fernandez, J., Sáenz, J., and Zorita, E.: Analysis of wintertime atmospheric moisture transport and its variability over southern Europe in the NCEP-Reanalyses, Climate Res., 23, 195-215, 2003.

García-Herrera, R., Paredes, D., Trigo, R. M., Trigo, I. F., Hernández, E., Barriopedro, D., and Mendes, M. A.: The Outstanding 2004/05 Drought in the Iberian Peninsula: Associated Atmospheric Circulation, J. Hydrometeorol., 8, 483-498, 2007.

Gimeno, L., Nieto, R., Trigo, R., Vicente-Serrano, S. M., and López-Moreno, J. I.: Where does the Iberian Peninsula moisture come from? An answer based on a Lagrangian approach, J. Hydrometeorol., 11, 421-436, 2010.

Huffman, G. J., Adler, R. F., Morrissey, M. M., Curtis, S., Joyce, R., McGavock, B., and Susskind, J.: Global precipitation at one- degree daily resolution from multisatellite observations, J. Hydrometeorol., 2, 36-50, 2001.

Knippertz, P. and Martin, J. E.: Tropical plumes and extreme precipitation in subtropical and tropical West Africa: Part 1, Moisture transport and precipitation generation, Quart. J. Roy. Meteor. Soc., 131, 2337-2365, 2005.

Lionello, P., Malanotte-Rizzoli, P., Boscolo, R., Alpert, P., Artale, V., Li, L., Luterbacher, J., May, W., Trigo, R., Tsimplis, M., Ulbrich, U., and Xoplaki E.: The Mediterranean climate: an overview of the main characteristics and issues, in: Mediterranean climate variability edite by: Lionello P., MalanotteRizzoli, P., and Boscolo, R., Elsevier, Amsterdam, 1-26, 2006.

Liu, J. and Stewart, R. E.: Water vapour fluxes over the Saskatchewan River basin, J. Hydrometeorol., 4, 944-959, 2003.

Mariotti, A., Struglia, M. V., Zeng, N., and Lau, K.-M.: The Hydrological Cycle in the Mediterranean Region and Implications for the Water Budget of the Mediterranean Sea, J. Climate, 15, 1674-1690, 2002.

Newell, R. E., Newell, N. E., Zhu, Y., and Scott, C.: Tropospheric rivers?, A pilot study, Geophys. Res. Lett., 19(24), 2401-2404, 1992.

Nieto, R., Gimeno, L., and Trigo, R. M.: A Lagrangian identification of major sources of Sahel moisture, Geophys. Res. Lett., 33, L18707, doi:10.1029/2006GL027232, 2006.

Nieto, R., Gimeno, L., Gallego, D., and Trigo, R.: Contributions to the moisture budget of airmasses over Iceland, Meteorol. Z., 16(1), 37-44, 2007.

Nieto, R., Gallego, D., Trigo, R., Ribera P., and Gimeno, L.: Dynamic identification of moisture sources in the Orinoco basin in equatorial South America, Hydrolog. Sci. J., 53(3), 602-617, 2008 .

Nieto, R., Gimeno, L., Drumond, A., and Hernandez, E.: A Lagrangian identification of the main moisture sources and sinks affecting the Mediterranean area, WSEAS Transactions on Environment and Development, 5(6), 365-374, 2010.

Numaguti, A.: Origin and recycling processes of precipitating water over the Eurasian continent: Experiments using an atmospheric general circulation model, J. Geophys. Res., 104, 1957-1972, 1999.

Peixoto, J. P., De Almeida, M., Rosen, R. D., and Salstein, D. A.: Atmospheric moisture transport and the water balance of the Mediterranean Sea, Water Resour. Res., 18, 83-90, 1982.

Reale, O. and Shukla, J.: Modeling the effects of vegetation on Mediterranean climate during the Roman classical period: Part II, Model simulation, Glob. Planet Change, 25, 185-214, 2000.

Santos, J., Corte-Real, J., and Leite, S.: Atmospheric large-scale dynamics during the 2004/2005 winter drought in Portugal, Int. J. Climatol., 27(5), 571-586, 2007.

Sodemann, H. and Zubler, E.: Seasonal and inter-annual variability of the moisture sources for Alpine precipitation during 19952002, Int. J. Climatol., 30, 947-961, 2010.

Sodemann, H., Schwierz, C., and Wernli, H.: Interannual variability of Greenland winter precipitation sources: Lagrangian moisture diagnostic and North Atlantic Oscillation influence, J. Geophys. Res., 113, D03107, doi:10.1029/2007JD008503, 2008a.

Sodemann, H., Masson-Delmotte, V., Schwierz, C., Vinther, B. M., and Wernli, H.: Interannual variability of Greenland winter precipitation sources: 2, Effects of North Atlantic Oscillation variability on stable isotopes in precipitation, J. Geophys. Res., 113, 
D12111, doi:10.1029/2007JD009416, 2008b.

Stohl, A.: Computation, accuracy and applications of trajectories a review and bibliography, Atmos. Environ., 32, 947-966, 1998.

Stohl, A. and James, P.: A Lagrangian analysis of the atmospheric branch of the global water cycle, Part 1: Method description, validation, and demonstration for the August 2002 flooding in central Europe, J. Hydrometeorol., 5, 656-678, 2004.

Stohl, A. and James, P.: A Lagrangian analysis of the atmospheric branch of the global water cycle, Part 2: Earth's river catchments, ocean basins, and moisture transports between them, J. Hydrometeorol., 6, 961-984, 2005.

Stohl, A. and Thomson, D. J.: A density correction for Lagrangian particle dispersion models, Bound.-Lay. Meteorol., 90, 155-167, 1999.

Stohl, A., Forster, C., Frank, A., Seibert, P., and Wotawa, G.: Technical note: The Lagrangian particle dispersion model FLEXPART version 6.2, Atmos. Chem. Phys., 5, 2461-2474, doi:10.5194/acp-5-2461-2005, 2005.
Trenberth, K. E.: Atmospheric moisture recycling: Role of advection and local evaporation, J. Climate, 12, 1368-1381, 1999.

Trigo, R. M., Osborn, T. J., and Corte-Real, J.: The North Atlantic Oscillation influence on Europe: climate impacts and associated physical mechanisms, Clim. Res., 20, 9-17, 2002.

Vogelezang, D. H. P. and Holtslag, A. A. M.: Evaluation and model impacts of alternative boundary-layer height formulations, Bound.-Lay. Meteorol., 81, 245-269, 1996.

Ward, M. N.: Diagnosis and short-lead predictions of summer rainfall in tropical North Africa at interannual and multidecadal timescales, J. Climate, 11, 3167-3191, 1998.

White, P. W.: IFS documentation, ECMWF Rep., Reading, United Kingdom, 2002.

Zhu, Y. and Newell, R. E.: A Proposed Algorithm for Moisture Fluxes from Atmospheric Rivers, Mon. Weather Rev., 126, 725735, 1998. 